\title{
Editorial 21/3
}

\section{Hubert Österle • Karen Heyden}

Published online: 31 August 2011

(C) Institute of Information Management, University of St. Gallen 2011

Dear Readers of Electronic Markets,

Many of you might already have joined social networks, such as Facebook, Twitter or LinkedIn. As this special issue of Electronic Markets shows, these social networks have implications on several aspects of electronic commerce. In particular, they allow including (end) customers more actively in all kinds of value creation processes. Consumers interact among themselves and with businesses on the oneto-one-basis which has become a well-known goal in marketing.

This special issue focuses on this exciting area of networking with customers. Put together by our guest editors, Thomas Hess, Karl R. Lang and Sean Xin Xu, we are happy to present you three contributions in the area of "Social embeddedness and online consumer behavior". As usual, a more comprehensive introduction is given by the guest editors prior to their special section. We highly appreciate their enthusiasm in organizing this issue and would like to thank all reviewers who made it possible.

A fourth research paper comes in the general research section. "Understanding auction fever: a framework for

\footnotetext{
H. Österle $(\bowtie)$

Institute of Information Management, University of St. Gallen, Müller-Friedberg-Strasse 8,

St. Gallen 9000, Switzerland

e-mail: hubert.oesterle@unisg.ch

\section{K. Heyden}

Information Systems Institute, University of Leipzig,

Grimmaische Str. 12,

Leipzig 04109, Germany

e-mail: heyden@wifa.uni-leipzig.de
}

emotional bidding" describes a conceptual framework that helps to analyze emotions in auctions. The ultimate reason is to understand why bidders change an initially chosen bidding strategy. The authors, Marc T.P. Adam, Jan Krämer, Caroline Jähnig, Stefan Seifert and Christof Weinhardt, suggest three stages of auctions which trigger emotional processing.

Finally, we decided to revive the category of book reviews in Electronic Markets. A book that attracted much attention in the community is on "Business Networked Transformation: Business Network Transformation: Strategies to Reconfigure Your Business Relationships for Competitive Advantage". We feel that this work written by Jeffrey Word from SAP ideally fits the mission of our journal. We would like to thank Christoph Riedl for contributing this review.

In addition, the Editorial Board Meeting took place in Bled, Slovenia, on June, 14 2011. During the past year Electronic Markets has seen more submissions and stricter acceptance rates. In general, $19 \%$ of the submissions were accepted for publication which means that $8 \%$ of general research submissions and $31 \%$ of special issue submissions were accepted. In future we also plan to nominate a "The paper of the year" to honor the best submission.

We hope you enjoy reading this issue of Electronic Markets. Any feedback on the journal, special themes or single contributions is greatly appreciated.

Best regards,

Your Electronic Markets editorial team

Hubert Österle

Karen Heyden 